\title{
ALGUMAS ANOTAÇŌES SOBRE OS CRIMES CONTRA OS COSTUMES
}

Prof. Titular L. A. MACHADO*

\author{
I - ESTUPRO \\ (art. 213)
}

1. BEM JURIDICO. A tutela penal dirige-se à proteção da livre disposição, pela mulher, do próprio corpo, em matéria sexual. Nesse contexto, mesmo a prostituta pode ser sujeito passivo do crime. Concomitantemente, a tutela penal alcança a integridade física e a liberdade sexual, ora caracterizando-se um crime complexo em sentido amplo (conjunção carnal com violencia presumida ou com grave ameaça), ora um tipo complexo em sentido estrito (estupro com violência real: constrangimento ilegal e lesões corporais.

2. SUJEITO ATIVO. O sujeito ativo do crime de estupro só pode ser o homem (tipo próprio; elemento modal quanto ao agente), ja que o tipo objetivo exige a relação sexual normal, heterossexual. Portanto, apenas como partícipe a mulher pode ser sujeito ativo desse delito. Quando a mulher pratica ato executivo inicial de relação sexual (beijo lascivo, sexo oral), dissociado da preparação, para o homem, da conjunção carnal elementar ao estupro, pratica o crime de atentado violento ao pudor (C. Penal, art. 214).

A doutrina controvertia sobre a possibilidade de o marido cometer estupro contra a própria mulher, na constância do casamento, tendo-se em conta os deveres de prestação sexual. FRAGOSO, por exemplo, entende inexistir crime quando o marido força, à conjunção carnal, a própria mulher, na constância da sociedade conjugal. MUNHOZ NETTO entendia haver o estupro no caso de a mulher recusar-se, com justa causa (marido portador de doença venérea, convalescença da mulher, etc.), à conjunção carnal. Entendo que, sempre que o marido use de violência ou grave ameaça para obter o favor sexual de sua mulher, estará cometendo o estupro. No caso de recusa constante e injustificada da mulher ao débito conjugal, há violação de deveres matrimoniais capazes de conduzir à dissolução do casamento, mas não para tornar l ícita a conduta penalmente ilícita do marido. A mulher tem o direito à recusa, em termos penais, sempre.

*Curso de Mestrado 
É possível que o autor da violência ou da grave ameaça seja outro, que não o autor da conjunção carnal, caracterizando um caso de concurso de agentes.

3. SUJEITO PASSIVO. O sujeito passivo é sempre a mulher, pouco importando ser, ou não, virgem; ser, ou não, honesta ou prostituta; ser criança, maior ou menor. Também é irrelevante que a vítima da violência ou da grave ameaça seja distinta da vítima do estupro, desde que aplicável o principio da identidade pessoal (a pessoa sacrificaria o mesmo bem jurídico em favor da ameaçada): mãe que suporta a conjunção carnal para que seu filho não seja denunciado por crime cometido, v. g.. 4. TIPO OBJETIVO. A ação consiste em constranger (obrigar, ccagir) mulher à conjunção carnal.

Conjunção carnal é o ato sexual normal, praticado por pessoas de sexos opostos (relação heterossexual normal). Imprescindivel a violência ou a grave ameaça à vítima ou a terceiro; a prática de outros atos sexuais (coito anal, felação, masturbação, v. g.), com violência ou grave ameaça, ou são in ício de execução do estupro ou caracterizam atentado violento ao pudor.

O estupro exige, como elemento do tipo objetivo, o dissenso da vítima. Por isso, o consentimento válido torna objetivamente atípica a conduta. $\mathrm{O}$ dissenso deve ser franco, positivo, militante. A oposição ao ato sexual deve ser séria (não bastando a mera simulação), mas não constante (persistência). Basta o quebrantamento inicial da vontade para que se caracterize o delito de estupro, sem que se possa exigir, da vítima, que aumente o seu sofrimento, obrigando-a a opor-se persistentemente.

5. TIPO SUBJETIVO. O tipo subjetivo porta, além do dolo (vontade livre e consciente de constranger mulher, por violência ou grave ameaça), a intenção do agente (fim de praticar a conjunção carnal).

6. CONSUMAC̣ÃO. TENTATIVA. A consumação do estupro fixa-se na "introductio penis ad vas", sendo desnecessária e irrelevante a "imissio seminis", mero exaurimento do delito.

A tentativa configura-se quando, praticados os atos libidinosos iniciais à conjunção carnal (toque vaginal, felação, p. e.), a ação interrompe-se casualmente, independente da vontade do agente.

7. CONCURSO DE CRIMES. Há concurso material de estupro com o crime de perigo de contágio venéreo (art. 130) e ultraje público ao pudor (art. 233). Representa, em relação ao crime de atentado violento ao pudor (art. 214), uma progressão criminosa.

\section{II - ATENTADO VIOLENTO AO PUDOR (art. 214)}

8. BEM JURIDICO. Liberdade sexual e integridade física.

9. SUJEITO ATIVO. Homem ou mulher, de qualquer idade ou condição. 
10. SUJEITO PASSIVO. Também homem ou mulher, de qualquer idade ou condição.

11. TIPO OBJETIVO. A ação é a de constranger alguém, por violência ou grave ameaça, a praticar, ou permitir que com ele se pratique, ato libidinoso diverso da conjunção carnal.

Ato libidinoso é a ação atentatória ao pudor, contato corporal não meramente fetichista. Segundo HUNGRIA, "é aquele que se apresenta como desafogo (completo ou incompleto) á concupiscência". Mas necessita ser objetivamente obsceno, além do que deve ser um fim em si mesmo, não um meio. São atos libidinosos, por exemplo, o toque vaginal, a masturbação, a felação.

Como no crime de estupro, o tipo objetivo exige o efetivo dissenso da vítima, sendo que o consentimento válido torna, a conduta, atípica. O constrangimento, pela violência ou pela grave ameaça, para que se presencie ato libidinoso (constranger alguém, por violência ou grave ameaça, a presenciar a masturbação alheia, v. g.) não caracteriza o crime de atentado violento ao pudor.

12. TIPO SUBJETIVO. O tipo subjetivo porta o dolo (vontade livre e consciente de compor o tipo objetivo) e a intenção (fim libidinoso).

13. CONSUMAÇĀO. TENTATIVA. A consumação está na efetiva prática do ato libidinoso ou no consentimento, viciado pela violência ou pela grave ameaça, para que se o pratique.

\section{III - POSSE SEXUAL MEDIANTE FRAUDE (art. 215)}

14. BEM JURIDICO. A liberdade sexual, protegida em relação ao vício de vontade da vítima.

15. SUJEITO ATIVO. Sempre o homem; a mulher, apenas como partícipe.

16. SUJEITO PASSIVO. O sujeito passivo do crime é sempre a mulher honesta. Neste conceito (elemento normativo sociológico, portanto extra-jurídico, do tipo) não se compreende apenas a de moral irrepreensivel, mas aquela que mantém um mínimo de decência.

17. TIPO OBJETIVO. A conduta consiste na manutenção da conjunção carnal através de fraude, que é o induzimento em erro da vítima, fazendo-a supor lícito o ato sexual. As hipóteses mais comuns são a de simulação de casamento e a de substituição de pessoa. Já é clássico o exemplo do feiticeiro que, a pretexto de expulsar o espírito mau da crente, com ela mantém conjunção carnal.

18. TIPO SUBJETIVO. O tipo subjetivo porta o dolo (vontade livre e consciente de praticar a ação) e a intenção (fim de conjunção carnal). 0 erro invencível quanto à honestidade da mulher exclui o dolo (momento de representação defeituoso); a dúvida caracteriza o dolo eventual, suficiente para amparar o tipo subjetivo.

19. CONSUMAÇÃO. TENTATIVA. A consumação ocorre no momen- 
to da "introductio penis intra vas", sendo desnecessária a "imissio seminis" (exaurimento).

20. FORMA QUALIFICADA. O art. 215, p. único, prevê a qualificação do crime, se a vítima é virgem e menor de dezoito anos e maior de quatorze anos. $\mathrm{O}$ agente deve conhecer a menoridade e a virgindade da vítima, além da sua honestidade (sobre o conceito de virgindade, v. infra $\left.\mathrm{n}^{0} .30\right)$. Se a vítima for menor de quatorze anos, haverá estupro por violência presumida (art. $213 \mathrm{c} / \mathrm{c}$ o art. 224).

\section{IV - ATENTADO VIOLENTO AO PUDOR MEDIANTE \\ FRAUDE (art. 216)}

21. BEM JURIIDICO. A liberdade sexual.

22. SUJEITO ATIVO. Qualquer pessoa, inclusive mulher (lésbica), embora geralmente seja o homem.

23. SUJEITO PASSIVO. Mulher honesta (v., supra, no. 16).

24. TIPO OBJETIVO. A ação consiste em, através de fraude, praticar ato libidinoso diverso da conjunção carnal; quando o ato libidinoso for praticado visando a conjunção carnal, haverá tentativa de posse sexual mediante fraude (v. supra no. 17).

25. TIPO SUBJETIVO. O tipo subjetivo porta o dolo (vontade livre e consciente de praticar a conduta descrita no tipo objetivo, de fraudar a vontade) e a intenção (fim de atentar ao pudor). O erro invencível quanto à honestidade da mulher exclui o dolo; a dúvida, caracteriza dolo eventual e, pois, fixa o tipo subjetivo.

26. CONSUMAÇÄO. TENTATIVA. O crime consuma-se com a efetiva prática do ato libidinoso. A tentativa, embora de configuração difícil, é admissível.

27. FORMA QUALIFICADA. Vítima maior de quatorze e menor de dezoito anos: o dolo deve abranger essa circunstância. Caso a vítima seja menor de quatorze anos, o crime é o de atentado violento ao pudor, por violência presumida (art. 214 c/c o art. 224).

$$
\begin{gathered}
\text { V - SEDUÇĀO } \\
\text { (art. 217) }
\end{gathered}
$$

28. BEM JURIDICO. Moralidade pública e bons costumes, na evidência do interesse público quanto à integridade sexual das menores (FRAGOSO).

29. SUJEITO ATIVO. Pessoa do sexo masculino, tendo-se em conta que a relação heterossexual normal é elemento componente do tipo objetivo. O partícipe pode cometer o crime do art. 227.

30. SUJEITO PASSIVO. Mulher, virgem e com idade entre quatorze e dezoito anos. A integridade himenal pode ser prova da virgindade da mulher. É possível, porém, virgindade com hímen roto (v. g., traumatis- 
mo físico, masturbação com garrafa) e não virgindade com hímen íntegro (hímen complacente, que permite o ingresso do pênis sem se romper, ou hímen artificial). A virgindade, pois, pode não se relacionar com a integridade himenal, caracterizando-se, em verdade, pela inexperiência heterossexual vaginal da mulher.

A conjunção carnal com mulher não virgem é penalmente irrelevante, não podendo desaguar no delito de corrupção de menores, tendo em linha de consideração a precedente experiência sexual. 0 art. 218 não é subsidiário do art. 217 , como, erroneamente, pretende grande parte dos julgados dos nossos tribunais ( se não há este, há aquele).

$A$ idade deve estar compreendida entre quatorze e dezoito anos. A conjunção carnal com mulher menor de quatorze anos tipifica o crime de estupro (art. 213) com presunção de violência (art. 224). A prova da idade faz-se com certidão do registro das pessoas naturais, efetuado antes do crime, como tem exigido a jurisprudência.

A mulher deve ser honesta e recatada, portadora da inexperiência e capaz da justificada confiança. A Exposição de Motivos deixa claro que "o projeto não protege a moça que se convencionou chamar emancipada, nem tampouco aquela que, não sendo de todo ingênua, se deixa iludir por promessas evidentemente insinceras" (Exposição de Motivos, no. 71).

31. TIPO OBJETIVO. O tipo objetivo compreende tanto a sedução simples (abuso da inexperiência e simplicidade da vítima) como a qualificada (engano da vítima) (FRAGOSO). Ainda FRAGOSO: "seduzir significa desviar, atrair, viciar ou dominar a vontade da ofendida".

A conjunção carnal deve ser causal ao abuso da inexperiência ou da justificada confiança da vítima. Inexperiência é "a incapacidade de avaliação ética do ato sexual e suas conseqüências" (FRAGOSO). A vítima não sabe o seu verdadeiro significado moral e social. Hoje pode-se dizer impossível a sedução simples. Os casos de moças ingênuas, inexperientes, podem relacionar-se de perto com a presunção de violência (art. 224), caracterizadora do estupro. Só há, hoje, inexperiência relacionada à debilidade mental.

$\mathrm{Na}$ justificada confiança a mulher tem a representação do ato sexual e das suas conseqüências, mas a sua vontade está aliciada, enganada, pela promessa de casamento. Como bem diz FRAGOSO, só é possível a sedução qualificada quando a confiança justificada se embase em promessa de casamento séria. A promessa de casamento feita "aestuante libidine", regra geral, pela sua objetiva insinceridade, não possui relevância penal.

A confiança justificada deve sofrer exame objetivo, pouco importando a sua credibilidade subjetiva para a vítima. Interessa a credibilidade objetiva no contexto cirdundante.

Não há sedução continuada pela simples razão da inexistência de virgindade nos atos subsequentes de conjunção carnal. Pode, no entanto, existir concurso material (art. 51) com o crime de perigo de contágio venéreo (art. 130) e com o crime de corrupção de menores (art. 218). 
32. TIPO SUBJETIVO. Dolo (vontade livre e consciente de seduzir mulher virgem, maior de quatorze e menor de dezoito anos, abusando da sua inexperiência ou justificável confiança) e intenção (fim de manter a conjunção carnal).

33. CONSÚMAÇĀO. TENTATIVA. O delito consuma-se com a conjunção carnal, completa ou incompleta, que se verifica com a efetiva introdução do órgão genital masculino no feminino. É irrelevante a "imissio seminis".

A tentativa é admissível.

\section{VI - CORRUPÇÃO DE MENORES (art. 218)}

34. BEM JURIDICO. A moralidade publica e os bons costumes e a integridade moral, em relação à iniciação precoce de menores em atos libidinosos.

35. SUJEITO ATIVO. Qualquer pessoa, sem distinção de sexo.

36. SUJEITO PASSIVO. Qualquer pessoa, tanto do sexo masculino como do feminino, maior de quatorze e menor de dezoito anos. Os menores de quatorze anos, na forma de presenciar, estão penalmente desprotegidos, o que mereceu correta crítica de NORONHA

37. TIPO OBJETIVO. A ação consiste em corromper (desnaturar, perverter ) ou facilitar a corrupção (coadjuvar, favorecer, prestar aux ílio). A corrupção é tanto a física (perversão ou perda da castidade corporal) como a moral (perversão dos sentimentos ou do pudor) e é presumida "juris et de jure", sem a necessidade da efetiva ocorrência, bastando a idoneidade da ação. A corrupção de menores é um crime de perigo abstrato, presumido.

$\mathrm{O}$ ato libidinoso (elemento normativo extra-jurídico) vai desde o beijo lascivo (vulgarmente chamado de beijo de l'íngua) até ao coito anal.

Três são as formas de atuação do agente: a) prática com ou contra menor ato de libidinagem; b) induz menor a praticar, em si ou em terceiro, ato de libidinagem; c) induz menor a presenciar ato de libidinagem praticado pelo próprio agente ou por terceiro. Quando o ato de libidinagem é praticado pelo menor no próprio agente, há necessidade de que este tome a iniciativa, sem o que não há o tipo.

No caso de a vítima já ser corrompida, não há o crime, embora o C. Penal brasileiro de 1940 não tenha nada semelhante ao art. 530 do italiano (exclui-se a punibilidade se o menor é pessoa já moralmente corrompida). HUNGRIA entende que só há corrupção completa, escapando da tutela penal, quando se trata de prostituta. FRAGOSO, ao contrário, diferencia a corrupção da prostituição: nesta, há venalidade, multiplicidade de homens recebidos e a liberdade de acesso promíscuo, traduzindo habitualidade e liberalidade. É preciso que se tenha presente não ser, o crime de corrupção de menores, subsidiário do de sedução. A conjunção carnal, elemento deste, deveria ser ato de corrupção ou 
de facilitação à corrupção, para se integrar àquele; portanto, ou constitui elemento do crime de sedução ou é penalmente irrelevante ('“fornicatio simplex de juris civilis prohibita non est"').

Continua com razão FRAGOSO quando define a corrupção como a perda da ingenuidade sexual, com o conhecimento dos prazeres da carne (MANFREDINI: experiência da vida carnal; MAGGIORE: experiência nos segredos do amor, sem exigência de ápice da arte erótica).

É possível o escalonamento da corrupção em graus, sempre que se pratique, com a vítima, uma nova modalidade de ato libidinoso. Segundo MANZINI, há maior corrupção quando o agente pratica, com a vítima, atos com que esta não está habituada a praticar. Consequentemente, não há crime quando o agente repete ato com que a vítima já se habituara. É bem de ver que não há corrupção quando se pratique, com a vítima, ato novo, porém menos corruptor do que se habituara a praticar (v. g., felação, após coito anal).

Não se exige a reiteração ou a habitualidade do ato libidinoso para que se configure o crime. A repetição do ato com a mesma vítima, à medida que represente quebrantamento de suas reservas morais e escalada na corrupção, pode configurar a forma continuada.

38. TIPO SUBJETIVO. O tipo subjetivo porta apenas o dolo (vontade livre e consciente de praticar a ação), sem qualquer intenção de corromper. $\mathrm{O}$ erro invencível quanto à menoridade ou condição moral da vítima exclui o dolo.

39. CONSUMAC̣ĀO. TENTATIVA. A consumação do crime dá-se com o ato libidinoso (na prática ou no induzimento - criação da vontade - à prática do ato) e no presenciar, na forma de induzimento a presenciar.

A tentativa é possível, pois a ação é fracionável, plurissubsistente. 40. FORMA ASSIMILADA. A lei no. 2.252, de 01.07.54, classifica, no art. 10 ., como corrupção de menor, a prática de infração penal (crime ou contravenção) com pessoa menor de dezoito anos, ou o induzimento à prática.

A pena é igual à prevista no art. 218 do C. Penal.

\section{VII - RAPTO VIOLENTO OU MEDIANTE FRAUDE (art. 219)}

41. BEM JURIDICO. No crime de rapto há imensa gama de interesses ofendidos. Daí porque poderia estar classificado entre os crimes sexuais, como entre os contra a liberdade individual ou contra a fam ília. $\mathrm{O}$ código italiano coloca o rapto violento ou fraudulento entre os crimes contra a liberdade sexual e o rapto consensual entre os crimes contra a família. Já o código alemão os coloca entre os crimes contra a liberdade individual. 
A tutela penal alcança a liberdade sexual, a organização da família e a liberdade física individual.

42. SUJEITO ATIVO. Qualquer pessoa (em regra, homem).

43. SUJEITO PASSIVO. Mulher honesta (elemento normativo extrajurídico, v. supra n? 16). A conduta contra mulher pública apenas caracteriza crime contra a liberdade individual. É irrelevante a idade e o estado civil da vítima.

44. TIPO OBJETIVO. A ação física consiste em raptar (subtrair, tirar a vítima da sua esfera de proteção legal ou zona de normalidade jurídica) com violência, grave ameaça ou fraude (violência é a força física necessária para vencer a resistência, é via de fato; grave ameaça é a violência moral, a perturbação da liberdade psíquica e da tranqüilidade da vítima; fraude é a apresentação de uma falsa aparência da realidade).

O crime pode se dar pela remoção "loco ad locum" ou pela "retentio". O rapto é um conceito jurídico que se não confunde com o deslocamento. Tanto há rapto no sequestro com fim libidinoso como, v. g., o dentista impedir a sa ída da cliente do consultório ("retentio") com o mesmo fim.

O tipo objetivo exige o dissenso efetivo e constante da vítima, pelo que o consentimento válido o exclui.

45. TIPO SUBJETIVO. O tipo subjetivo porta o dolo (vontade livre e consciente de raptar mulher honesta) e a intenção (fim libidinoso seu ou de terceiro).

46. CONSUMAC̣ĀO. TENTATIVA. O tipo é formal (consumação antecipada, resultado truncado), em que o tipo subjetivo vai além do objetivo (originariamente incongruente). Por isso, a consumação situa-se na subtração da mulher honesta, independentemente da efetiva prática do ato libidinoso. A tentativa é admissível.

\section{VIII - RAPTO CONSENSUAL (art. 220)}

47. BEM JURIDICO. Pátrio poder.

48. SUJEITO ATIVO. Qualquer pessoa.

49. SUJEITO PASSIVO. Mulher honesta entre quatorze e dezoito anos, que consente com a ação. Se for menor de quatorze anos, há violência presumida (art. 224) e o crime será o de rapto violento (art. 219). Menor emancipada consente validamente, inexistindo o tipo.

50. TIPO OBJETIVO. A ação física consiste em raptar, isto é, subtrair a menor da tutela do pátrio poder. 0 consentimento deve ser consciente, ainda que juridicamente inválido. No caso de a vítima procurar espontaneamente o agente, não há rapto e, portanto, não há o tipo objetivo.

$O$ rapto inicialmente consensual pode passar a violento, a partir do instante em que a mulher se veja obstada de desistir de consentir.

Na forma de retenção (também consensual), o crime é permanente. 
51. TIPO SUBJETIVO. Dolo (vontade livre e consciente de subtrair a menor do patrio poder) e intenção (fim libidinoso).

52. CONSUMAÇÃO. TENTATIVA. Vale, aqui, o que foi dito supra (nO. 46).

53. DIMINUIÇĀO DE PENA. São causas de especial diminuição de pena o fim de casamento (um terço) e a restituição da vítima à liberdade ou a sua colocação em lugar seguro, à disposipão da fam ília, sem ter praticado o ato libidinoso (metade). É o que os práticos chamavam de "restitutio in integrum" ou "repositio in pristinum statum".

A natureza jurídica da diminuição encontra-se na arrependimento eficaz (art. 15), em forma peculiar por não extinguir a punibilidade. E não a extingue, pelo gravame sexual que a vítima carrega.

Basta que o agente atue voluntariamente (sem coação), pouco importando o motivo da desistência (não se exige a espontaneidade, bastando a voluntariedade).

Embora a opinião de BENTO DE FARIA, de que o in ício do inquérito policial ou da ação penal torna inócua a "restitutio", a razão está com HUNGRIA ao pretender que a devolução, em qualquer época, beneficia o agente.

54. CONCURSO DE CRIMES. O art. 222 impõe o concurso material entre o rapto e outro crime, concomitante ou conexo, cumulando-se, assim, as penas (art. 51).

\section{IX - DISPOSIC̣ŌES GERAIS DOS CRIMES CONTRA OS COSTUMES}

55. FORMAS QUALIFICADAS. Quando a violência transcende o mero quebrantamento da resistência e resulta em lesões corporais de natureza grave (art. 223) ou em morte (art. 223, p. único), previsíveis (as lesões e ou a morte) e causais a ela (violência), os crimes contra os costumes assumem a forma qualificada. Em caso de ocorrência de lesões corporais de natureza grave, a pena varia entre um mínimo de quatro e um máximo de doze anos de reclusão (art. 223). Em caso de morte (art. 223, p. único), a pena varia entre um mínimo de oito e um máximo de vinte anos.

Se o resultado morte é alcançado dolosamente, o agente responde pelo crime de homic ídio qualificado (art. 121, § 20 .).

56. PRESUNÇĀO DE VIOLÉNCIA (art. 224). A validade da violência presumida (ou ficta) é altamente discutível. A máxima de CELSUS, de que o pupilo "nec volle, nec nolle" (nem quer, nem deixa de querer), é contestada, dentre outros, por HOMMEL (quem é incapaz de querer, é incapaz de não querer) e por CARRARA, que pergunta: se é admitida a violência ficta no estupro, por que não o é no furto?

A violência ficta funda-se: a) na idade (menor de quatorze anos), presunção relativa, dependente do arbítrio do legislador; b) em doença ou deficiência mental que, a exemplo do C. Penal suiço, exige o conhecimento pelo agente ("connaissant l'état de sa victime"). A simples dú- 
vida não basta; c) na impossibilidade de resistência, preordenada ou aproveitada pelo agente. Pode dar-se pela embriaguez completa, inconsciência por estupefacientes, imobilização por enfermidade, hipnose.

57. AC̣ÃO PENAL (art. 225). Regra geral a ação penal é privada, iniciando-se por queixa crime. Quando, porém, haja violência real (crime complexo, art. 103), a ação penal é pública incondicionada (jurisprudência pacífica do Supremo Tribunal Federal, abonada por FRAGOSO e TORNAGHI; contra, HUNGRIA e FREDERICO MARQUES, sem qualquer razão científica).

A ação penal também é pública (embora condicionada à representação do ofendido ou de seu representante legal) quando a vítima, ou seus pais, seja juridicamente miserável. A miserabilidade jurídica é comprovável por atestado expedido pela autoridade policial (C. Pr. Penal, art. $32, \S 20$. .).

Por último, é ainda pública incondicionada a ação penal em relação à prática do crime com abuso do pátrio poder ou da qualidade de padrasto, tutor ou curador.

58. AUMENTO DE PENA (art. 226). Configuram-se causas de especial aumento de pena (quarta parte), se: I - há concurso de agentes, sendo prescindível, para a sua configuração, a participação de todos nos atos de execução (FRAGOSO, em oposição a HUNGRIA); II - há violação do dever decorrente da autoridade do agente sobre a vítima, em conseqüência da qualidade de ascendente, pai adotivo, padrasto, irmão, tutor ou curador, preceptor ou empregador ou autoridade superior; III - o agente é casado. FRAGOSO entende que a interpretação teleológica do casamento abrange, para fins penais, a separação judicial impeditiva de novo casamento, porque entende que o fundamento da causa de especial aumento situa-se não só na maior imoralidade, como na impossibilidade de reparação do dano pelo casamento. Portanto, a separação judicial que possibilita novo casamento não caracteriza o aumento da pena. 59. EXTINÇÃO DA PUNIBILIDADE. $O$ art. 108, inciso VIII, preve a extinção da punibilidade pelo casamento do agente com a vítima. É um caso de relevância penal à reparação do dano. MANZINI fala em arrependimento eficaz, logo após a consumação do crime. Mister a efetiva celebração do casamento, sendo certo que a não aceitação, pela vítima, elimina a causa extintiva da punibilidade.

$\mathrm{O}$ casamento superveniente que, para o C. Penal italiano, exclui o crime (art. 544), implica tão só em exclusão da pena (FRAGOSO).

$\mathrm{O}$ casamento aproveita aos coautores. O contrário seria ver, no casamento, pena mais grave do que a de prisão (CARRARA).

$\mathrm{O}$ casamento da vítima com terceiro tem sido entendido pelo Supremo Tribunal Federal como causa de necessária ratificação da representação que, não ocorrendo, a anula, extinguindo, então e de conseqüência, a punibilidade (v. Sumula da Jurisprudência Predominante do Supremo Tribunal Federal, no. 338). A lei no. 6.416, de 24.05.77, legalizou essa interpretação pretoriana (redação dada ao inciso VIII do art. 107), limitando-a aos crimes não cometidos com violência ou grave 
ameaça. O prosseguimento da ação penal deve, de qualquer forma, ser requerido pela vítima até sessenta dias contados da celebração do seu casamento com o terceiro. O C. Penal de 1984 manteve essa regulamentação (Cf. art. 107, inciso VIII).

Curitiba, novembro de 1984. 